OPEN ACCESS

Edited by:

Eleanor Riley,

University of Edinburgh,

United Kingdom

Reviewed by:

Martin R. Goodier,

London School of Hygiene and

Tropical Medicine (LSHTM),

United Kingdom

Karl-Johan Malmberg,

Oslo University Hospital, Norway

*Correspondence:

Aura Muntasell

amuntasel/@imim.es

tThese authors share senior authorship

Specialty section

This article was submitted to NK and Innate Lymphoid Cell Biology,

a section of the journal

Frontiers in Immunology

Received: 12 September 2018

Accepted: 13 March 2019

Published: 03 April 2019

Citation:

Costa-García M, Ataya M, Moraru M,

Vilches C, López-Botet $M$ and

Muntasell A (2019) Human

Cytomegalovirus Antigen Presentation

by HLA-DR+NKG2C+ Adaptive NK

Cells Specifically Activates

Polyfunctional Effector Memory CD4+

$T$ Lymphocytes.

Front. Immunol. 10:687.

doi: 10.3389/fimmu.2019.00687

\section{Human Cytomegalovirus Antigen Presentation by HLA-DR+ NKG2C+ Adaptive NK Cells Specifically Activates Polyfunctional Effector Memory CD4+ T Lymphocytes}

\author{
Marcel Costa-García ${ }^{1}$, Michelle Ataya ${ }^{2}$, Manuela Moraru ${ }^{3}$, Carlos Vilches ${ }^{3}$, \\ Miguel López-Botet ${ }^{1,2 \dagger}$ and Aura Muntasell ${ }^{2 \star+}$
}

\footnotetext{
${ }^{1}$ Department of Experimental and Health Sciences, University Pompeu Fabra, Barcelona, Spain, ${ }^{2}$ Hospital del Mar Medical Research Institute (IMIM), Barcelona, Spain, ${ }^{3}$ Immunogenetics and HLA Laboratory, Instituto Hospital Universitario Puerta de Hierro, Majadahonda, Spain
}

Natural killer (NK) cells play a dual role in the defense against viral pathogens by directly lysing infected cells as well as by regulating anti-viral T cell immunity. Infection by human cytomegalovirus (HCMV) promotes a persistent expansion of NKG2C+ adaptive NK cells which have been shown to display enhanced antibody-dependent responses against infected targets and associated to viral control in transplanted patients. Based on gene expression data showing increased transcription of CIITA and several genes related to the $\mathrm{MHC}$ class II pathway in adaptive NK cells, we explored their putative capacity for antigen presentation to CD4+ T cells. Phenotypic analysis confirmed a preferential steady-state expression of HLA-DR by circulating NKG2C+ adaptive NK cells in healthy individuals. Expression of HLA-DR in NKG2C+ adaptive NK cells was variable and unrelated to the expression of activation (i.e., CD69 and CD25) or differentiation (i.e., FcR $\gamma$ chain, CD57) markers, remaining stable over time at the individual level. Incubation of purified NK cells with HCMV complexed with serum specific antibodies induced an up-regulation of surface HLA-DR concomitant to CD16 loss whereas no changes in CD80/CD86 co-stimulatory ligands were detected. In addition, surface CX3CR1 decreased upon antigen-loading while HLA-DR+ NK cells maintained a CCR7-, CXCR3 low homing profile. Remarkably, HCMV-loaded purified NK cells activated autologous CD4+ T cells in an HLA-DR dependent manner. The fraction of $T$ lymphocytes activated by antigen-loaded NK cells was smaller than that stimulated by monocyte-derived dendritic cells, corresponding to CD28-negative effector-memory CD4+ T cells with cytotoxic potential. Antigen presentation by NK cells activated a polyfunctional CD4+ T cell response characterized by degranulation (CD107a) and the secretion of Th1 cytokines (IFN $\gamma$ and TNF $\alpha$ ). Overall, our data discloses the capacity of NKG2C+ adaptive NK cells to process and present HCMV antigens to memory CD4+ cytotoxic T cells, directly regulating their response to the viral infection.

Keywords: human, natural killer cell, cytomegalovirus, HLA-DR, NKG2C, CD4 T cells 


\section{INTRODUCTION}

HCMV is a $\beta$-herpesvirus that establishes a highly prevalent and generally asymptomatic life-long persistent infection in immunocompetent individuals, alternating subclinical reactivations and latency periods (1). HCMV infection is the leading infectious etiology of congenital sensorineural disabilities and an important co-morbidity in immunocompromised individuals (2-4). HCMV infection control involves the participation of specific $\mathrm{T}$ lymphocytes, antibodies, and NK cells, being an environmental factor significantly influencing the configuration of the immune system at individual level (5). Relatively high proportions of HCMV-specific CD8+ and $\mathrm{CD} 4+\mathrm{T}$ cells are found in peripheral blood of healthy HCMV+ individuals and tend to increase in the elderly, presumably as a result of a continuous virus-host interaction (6-9). HCMV seropositivity is associated to phenotypic and functional changes in specific CD4+ $\mathrm{T}$ cells with the variable expansion of an effector-memory population showing a Th1 cytokine profile and the loss of costimulatory molecules (CD28, CD27) concomitant to the acquisition of cytotoxic capacity (10-14). On the other hand, HCMV induces in some individuals a stable adaptive expansion of an NK cell subset, characterized by high surface levels of the activating receptor CD94/NKG2C in the absence of its inhibitory counterpart CD94/NKG2A (15). Differentiation of HCMV-adaptive NK cells is a progressive process which shapes their phenotypic and functional profile, involving the epigenetic regulation of transcription factors and signaling molecules. Adaptive NK cells preferentially express inhibitory killer Ig-like receptor (KIR) specific for self-HLA-C along with reduced NKp30, NKp46, and CD161 surface levels, and include high proportions of LILRB1+, CD57+, and Fc\&RI $\gamma$ cells (15-19). Functionally, NKG2C+ adaptive NK cells are proficient effectors, showing enhanced cytokine secretion (i.e., TNF $\alpha$ and IFN $\gamma$ ), cytotoxic potential (granzyme B) and antibody-dependent anti-viral responses (20-22). Expansions of NKG2C+ adaptive NK cells in kidney transplant recipients have been associated to a lower incidence of post-transplant HCMV viremia, indirectly suggesting that they may be involved in controlling viral reactivation (23).

A relative enrichment for distinct MHC class II-related transcripts, including the master transactivator CIITA, were detected in adaptive NK cells $(24,25)$. Generally, HLA class II molecules are constitutively expressed by professional APC (e.g., dendritic and B cells), yet can be induced upon activation in a variety of other cell types, including $\mathrm{T}$ and $\mathrm{NK}$ cells (26). Co-expression of HLA-DR and activation markers (i.e., CD69, CD11c) in circulating NK cells was described in patients with HIV-caused immunodeficiency (27), multiple sclerosis (28), or systemic lupus erythematosus (29). In healthy individuals, HLA-DR expression has been described in CD56 $6^{\text {bright }} \mathrm{NK}$ cells $(30,31)$, albeit relatively high levels of HLA-DR were also observed in CD56 ${ }^{\mathrm{dim}} \mathrm{NK}$ cells from some individuals. Few studies have evaluated HLA class II function on NK cells in the context of superantigen-dependent $\mathrm{T}$ cell activation (32), mixed lymphocyte reactions (33), or using synthetic peptides derived from immunodominant antigens (34). Recent studies reported a regulatory role for non-conventional HLA class II expression in steady-state type 2 and 3 innate lymphoid cell subsets $(35,36)$.

In the present study we have characterized the expression of HLA class II molecules by circulating adaptive NK cells in healthy individuals and their function as non-conventional antigen presenting cells (APC). We showed that NKG2C+ adaptive NK cells can present HCMV-derived antigens through HLA-DR to specific CD4+ T cells, a process that is enhanced by the presence of specific antibodies. Our results reveal a novel mechanism potentially involved in the crosstalk between adaptive NK cells and specific memory CD4 $+\mathrm{T}$ cells along persistent HCMV infection.

\section{MATERIALS AND METHODS}

\section{Subjects and Ethics Statement}

PBMC and serum samples used in this study were obtained from volunteer healthy adults. HCMV seropositive individuals showing $\geq 20 \%$ NKG2C+NKG2A- NK cells were considered to display adaptive NK cell expansions in contrast to seropositive donors with $<5 \%$ NKG2C+NKG2A- cells in their NK cell repertoire, considered to lack HCMV-adaptive expansions. Written informed consent was obtained from every donor, and the study protocol was approved by the local ethics committee (Clinical Research Ethics Committee, Parc de Salut Mar n²013/5470/I).

\section{Antibodies and Immunophenotyping by Flow-Cytometry}

FACS analysis was performed using mAbs specific for the following molecules: HLA-DR-fluorescein isothiocyanate (FITC), CD86-FITC, CD45RA-FITC, Perforin-FITC, CD69Phycoerythrin (PE), CD80-PE, IFN $\gamma$-PE, CD4-allophycocyanin (APC), CD3-peridinin-chlorophyll protein (PerCP), CCR7PE-Cy7, CD16-PE-Cy7, CD8-V500, CD28-PE-CF594 (BD Biosciences, San Diego, CA), CD56-APC, CD25-PE, CX3CR1PE-Cy7, CXCR3-eFluor 660 (eBioscience, San Diego, CA), NKG2C-PE (clone 134591), NKG2C-Alexa Fluor 700 (clone 134591) and unlabeled-NKG2C (clone MAB1381; R\&D Systems, Minneapolis, MN), anti-FceRI Ab, $\gamma$ subunit-FITC (Merck, Millipore), CD4-FITC, CD4-PE-Cy7, Granzyme B-Pacific Blue (PB; Biolegend, San Diego, CA), and NKG2D-APC (Miltenyi Biotec, Bergisch Gladbach, Germany). Anti-TNF- $\alpha$ (infliximab; REMICADE) was directly labeled with CF-Blue by Immunostep (Salamanca, Spain). Anti-NKp46 (clone Bab281) and anti-NKp30 (AZ20) mAbs were kindly provided by Dr. A. Moretta (University of Genova, Genova, Italy); anti-CD57 (clone HNK-1), anti-LILRB1 (clone HP-F1), and anti-CD161 (clone HP-3G10) were produced in our laboratory and employed as hybridoma culture supernatants. Cells were pre-treated with human aggregated $\operatorname{IgG}(10 \mu \mathrm{g} / \mathrm{ml})$ to block Fc receptors and subsequently labeled with specific Abs. For indirect immunostaining, samples were incubated with primary Abs followed by PE-Cy7-conjugated or APC-Cy7-conjugated $\mathrm{F}\left(\mathrm{ab}{ }^{\prime}\right) 2$ polyclonal goat antimouse IgG (Biolegend). Samples were acquired in LSRII or LSRFortessa flow cytometers (BD Biosciences), and data analyzed with FlowJo software (Tree 
Star). For blocking experiments, the anti-HLA-DR D1.12, kindly provided by Dr. R. Accolla (Università of Insubria, Varese) or an isotype control were used at saturating concentration. Mean Fluorescence Index for HLA-DR was calculated as previously described (37) using the following formula: mean fluorescence positive-mean fluorescence negative control/ $(2 \times$ Standard Deviation mean fluorescence negative control).

\section{HCMV Stock Preparation}

The MRC5 fetal human lung fibroblast cell line was obtained from the American Type Culture Collection (Manassas, VA) and grown in DMEM supplemented with $10 \%$ fetal bovine serum (FBS), penicillin, and streptomycin. Purified stocks of HCMV AD169 strain were prepared by infecting MRC5 cells at 0.25 multiplicity of infection (MOI) and harvesting supernatants when maximum cytopathic effect was reached. Cells and debris were removed from virus containing supernatant by centrifugation $10 \mathrm{~min}$ at $5000 \mathrm{x} \mathrm{g}$ and stored at $-80^{\circ} \mathrm{C}$. Viral stocks were titrated on MRC5 cells analyzed by detection of IE-1/IE-2 viral antigens with specific $\mathrm{mAb}$ (clone mab810; Millipore) by immunofluorescence as previously described (38).

\section{Primary NK Cell and CD4+ T Cell Purification}

Peripheral blood mononuclear cells (PBMC) were obtained from heparinized blood samples by separation on Ficoll-Hypaque gradient (Lymphoprep; Axis-Shield PoC AS, Oslo, Norway). Serum samples were collected, heat-inactivated and aliquoted before storage at $-20^{\circ} \mathrm{C}$. Standard clinical diagnostic tests were used to determine HCMV specific IgG titer (Roche Diagnostics, Basel, Switzerland). PBMC were kept overnight with complete RPMI 1640 medium supplemented with 200 $\mathrm{U} / \mathrm{ml}$ of recombinant human interleukin-2 (rhIL-2; Proleukin, Chiron, Emeryville, CA prior to proceeding with NK cell, or CD4+ T cell purification. NK cells were purified by negative selection using NK Cell Isolation kit (Miltenyi) according to the manufacturer instructions. Of note, some of the commercially available kits for NK cell isolation through negative selection include anti-HLA-DR antibodies resulting in the depletion of HLA-DR+ NK cells from the isolated pool, as also observed by Kovalenko et al. (39).

Autologous CD4 $+\mathrm{T}$ cells purified by negative selection using the CD4+ T cell Isolation Kit (Miltenyi) or PBMC (5:2 E:T ratio) were used as effector cells in functional assays.

Monocyte-derived dendritic cells (moDCs) were generated as previously described (40); briefly, monocytes were positively selected from fresh PBMCs using anti-CD14 microbeads (StemCell Technologies, Grenoble, France), and cultured for 6 days in RPMI 1650 medium supplemented with $10 \%$ FBS, interleukin-4 (IL-4; $25 \mathrm{ng} / \mathrm{ml}, \mathrm{R} \& \mathrm{D}$ Systems), and granulocyte-macrophage colony-stimulating factor (GM-CSF; 50 ng/ml, PeproTech).

\section{CD4+ T Cell and NK Cell Expansions}

HCMV-specific CD4+ T cells were expanded by incubating PBMC with HCMV virion preparations $\left(2 \times 10^{5} \mathrm{PFU} / 3 \times 10^{6}\right.$ cells) in 24-well plates. Cell cultures were maintained at $37^{\circ} \mathrm{C}$ in a $5 \% \mathrm{CO}_{2}$ humid atmosphere for 10-12 days. At day 3, cell cultures were supplemented with $25 \mathrm{U} / \mathrm{mL}$ of rhIL2 and half of the supernatant was replaced with fresh rhIL2-containing medium every 3 days; proliferating cell cultures were eventually split when required.

NK cells were expanded by incubating PBMC with irradiated HLA-E + 721.221-AEH lymphoblastoid cell line (41) in 24-well plates (3:1 ratio) in complete RPMI 1640 medium. Cell cultures were maintained at $37^{\circ} \mathrm{C}$ in a $5 \% \mathrm{CO}_{2}$ humid atmosphere for $10-$ 12 days; every 3 days half of the supernatant was replaced with fresh medium; when high cell density was attained, cell cultures were split. Expanded NK cells were further purified using the corresponding enrichment kit.

\section{Antigen-Presentation Assays}

NK cells or moDCs were cultured overnight with titrated HCMV preparations at MOI 2.5 in the presence or absence of $10 \%$ sera from HCMV+ donors. Subsequently, antigen-loaded or control APCs were incubated with autologous CD4+ T cells or PBMC (5:2 E:T ratio) for $18 \mathrm{~h}$ at $37^{\circ} \mathrm{C}$ in the presence of Brefeldin A $(10 \mu \mathrm{g} / \mathrm{ml}$; Sigma-Aldrich). Next, cells were stained with antibodies recognizing surface markers, fixed, permeabilized (fixation/permeabilization kit; eBioscience), stained with anti-TNF $\alpha$ and anti-IFN $\gamma$, and analyzed by flow cytometry. In some experiments, CD $4+\mathrm{T}$ cell degranulation was monitored by measuring CD107a mobilization with the additional presence of monensin $(5 \mu \mathrm{g} / \mathrm{ml}$; Sigma-Aldrich) and CD107a-FITC (BD Biosciences Pharmingen, San Diego, CA). Boolean gating function was used to identify all possible combinations of markers stained for on $\mathrm{CD} 3+\mathrm{CD} 4+\mathrm{T}$ cell populations (Flowjo software). In antigen presentation assays, $122,400 \pm 31,907$ total CD3 $+\mathrm{CD} 4+\mathrm{T}$ cells and 1,029 \pm 293 of activated CD3 + CD4 $+\mathrm{T}$ cells were acquired (mean \pm SEM). In some experiments, chloroquine $(50 \mu \mathrm{M})$ was added along NK cell incubation with HCMV preparations. NK cells were incubated with pp65 and IE1 overlapping peptide mixtures as control in some antigen presentation experiments (PepTivator CMV pp65 human, PepTivator CMV IE-1 human, Miltenyi).

\section{Statistical Analysis}

Statistical analysis was performed by the Mann Whitney U test using GraphPad Prism 5 software. Results were considered significant at the two-sided P level of 0.05 .

\section{RESULTS}

\section{HLA-DR Is Detected in Circulating NKG2C+ Adaptive NK Cells Uncoupled From Activation and Differentiation Markers}

The analysis of published transcriptional programs of adaptive NK cells, defined as CD56 ${ }^{\text {dim }}$ NKG2C+ $\left(\right.$ CD57+/FceRI $\left.\gamma_{-}\right)(24$, 25), identified transcripts for CIITA, HLA-DQ, HLA-DP, HLADMA, and HLA-DRA to be enriched in this NK cell subset 
(Supplementary Figure 1). In order to ascertain the predicted expression of MHC class II molecules on adaptive NK cells, we analyzed by flow cytometry HLA-DR in circulating NK cells from healthy individuals, stratified by the presence or absence of NKG2C+ adaptive NK cell expansions, according to the criteria described in Materials and Methods. As shown in Figure 1, HLA-DR was expressed in approximately $\sim 50 \%$ of circulating CD56 $6^{\text {bright }} \mathrm{NK}$ cells in all analyzed donors. In contrast, the proportions of HLA-DR + CD56 ${ }^{\text {dim }}$ NK cells varied in different individuals and were generally higher in $\mathrm{HCMV}+$ donors coinciding with the expansion of NKG2C+ adaptive NK cells, as compared to individuals lacking this phenotype regardless of their HCMV serostatus (Figures 1A-B and Supplementary Figure 2). Of note, proportions of HLA$\mathrm{DR}+\mathrm{NKG} 2 \mathrm{C}+\mathrm{NK}$ cells remained stable over time (Figure 1C) and were unrelated to the expression of activation markers (i.e., CD69 and CD25) (Figure 1D).

$\mathrm{HCMV}$-adaptive NKG2C+ NK cells have been proposed to undergo a sequential differentiation associated to the down-regulation of FceRI $\gamma, \mathrm{NKp} 30, \mathrm{NKp} 46$, and CD161 expression and the acquisition of CD57 and LILRB1 $(16,20,42)$. Since proportions of HLA-DR+ NKG2C+ adaptive NK cells varied between different individuals, we analyzed whether expression of HLA-DR coincided with the acquisition of a specific differentiation molecular signature. Expression of KIR, CD57, LILRB1, NKp30, NKp46, CD161, and FceRI $\gamma$ and HLA-DR was analyzed in NK cells from five $\mathrm{HCMV}+$ individuals displaying $\mathrm{NKG} 2 \mathrm{C}+$ adaptive $\mathrm{NK}$ cell expansions. The distribution of all assessed markers was comparable in HLA-DR+ and HLA-DR- NKG2C+ adaptive NK cells (Figure 2A). NKG2C-negative adaptive NK cell expansions have also been previously characterized for their oligoclonal KIR expression profile (17) and/or the loss of signaling adaptors such as FceRI $\gamma$ chain $(20,24,43)$. Detailed analysis of HLA-DR expression in two individuals concomitantly displaying NKG2C+ and NKG2C- FceRI $\gamma$ NK cell subpopulations confirmed the preferential expression of HLA-DR in adaptive NKG2C $+\mathrm{NK}$ cells independently of FceRI $\gamma$ levels in these cases (Figure 2B). Altogether, these results indicate that HLA-DR expression in NKG2C+ adaptive NK cells occurs dissociated from other differentiation/ adaptive features.

\section{Sensing of HCMV-antibody Immune Complexes Upregulates HLA-DR in NKG2C+ Adaptive NK Cells in the Absence of CD80/CD86 Expression}

We have previously shown that NK cells can directly sense the presence of HCMV virions and HCMV-antibody immune complexes (IC) $(21,44)$. We next addressed whether co-culture of primary NK cells with these stimuli could lead to HCMV antigen presentation by HLA class II molecules. To address this question purified NK cells were cultured overnight with HCMV (AD169 strain at MOI 2.5), including or not serum from seropositive donors. For comparison, autologous moDC were cultured in parallel in the same conditions. Incubation with HCMV did not result in NK cell or moDC infection, assessed by IE-1/IE-2 expression (not shown).

Up-regulation of surface HLA-DR, CD80, and CD86 in moDC was detectable following overnight co-culture with HCMV preparations, yet no significant changes were noticed in NK cells. In contrast, stimulation with HCMV in the presence of $\mathrm{HCMV}+$ serum promoted an up-regulation of surface HLA-DR in both NK and moDC, enhancing CD80/86 expression in the latter (Figures 3A,B and not shown). Among CD56 ${ }^{\mathrm{dim}} \mathrm{NK}$ cells, enhancement of surface HLA-DR expression was more evident in the NKG2C+ adaptive subset in concordance with their higher baseline expression (Figure 3C). Of note, a reduction of surface CD16 (Figure 3D) and the production of TNF $\alpha$ (not shown) (21) was detected upon overnight culture indicating NK cell sensing of HCMV-antibody immune complexes. Overnight incubation with HCMV immune complexes did not alter CCR7 expression, though surface CXCR3 and CX3CR1 was reduced in CD56 ${ }^{\mathrm{dim}} \mathrm{NK}$ cells after antigen loading (Figures 3E-H).

\section{HCMV Antigen-Loaded NK Cells Activate HCMV-Specific CD4+ T Cells in an HLA-DR-Dependent Manner}

Purified primary NK cells from individuals with NKG2C+ adaptive NK cell expansions and moDCs were pre-incubated overnight with HCMV in the presence or absence of HCMV+ sera and subsequently used as APCs in co-cultures with autologous primary CD4+ $\mathrm{T}$ lymphocytes. CD4+ $\mathrm{T}$ cell activation was monitored through the production of intracellular $\mathrm{TNF} \alpha$ and IFN $\gamma$ at $20 \mathrm{~h}$ by flow cytometry (Figure 4). Coculture with autologous CD4+ T lymphocytes did not promote cytokine production by NK cells (not shown). However, NK cells pre-incubated with HCMV viral particles triggered the activation of a small fraction of CD4+ T lymphocytes, as detected by the simultaneous production of $\mathrm{TNF} \alpha$ and IFN $\gamma$; higher proportions of CD4 $+\mathrm{T}$ cells were activated by $\mathrm{NK}$ cells antigen-loaded in the presence of $\mathrm{HCMV}+$ donor serum (Figures $4 \mathbf{A}, \mathbf{B}$ ). The average proportion of CD4+ $\mathrm{T}$ cells activated by virus-loaded moDC was 10-fold higher than that induced by antigen-presenting $\mathrm{NK}$ cells, and was not enhanced by $\mathrm{HCMV}+$ sera (Figures $4 \mathrm{~A}, \mathbf{B}$ ). Of note, in functional assays including autologous PBMC as effectors, only $\mathrm{CD} 4+$ but not CD8+ $\mathrm{T}$ cell activation could be detected upon co-culture with HCMV-loaded NK cells (Figure 4C). In fact, NK cell-induced CD4+ T cell activation was partially blocked by an $\alpha$-HLA-DR antibody (Figure 4D) and could not be detected in experiments with cells from HCMVseronegative donors, emphasizing the importance of HLA$\mathrm{DR}$ in antigen presentation and supporting the requirement of an expanded pool of antigen-experienced CD4+ $\mathrm{T}$ cells (Figure 4E). The addition of chloroquine, an inhibitor of endosomal and lysosomal acidification, along NK cell-loading with HCMV, partially prevented $\mathrm{CD} 4+\mathrm{T}$ cell activation. In contrast, presentation of peptide mixtures spanning pp65 and IE-1 immunodominant HCMV antigens to CD4+ T cells was unaffected by the drug (Figure 4F). Of note, analysis 
A HCMV seronegative

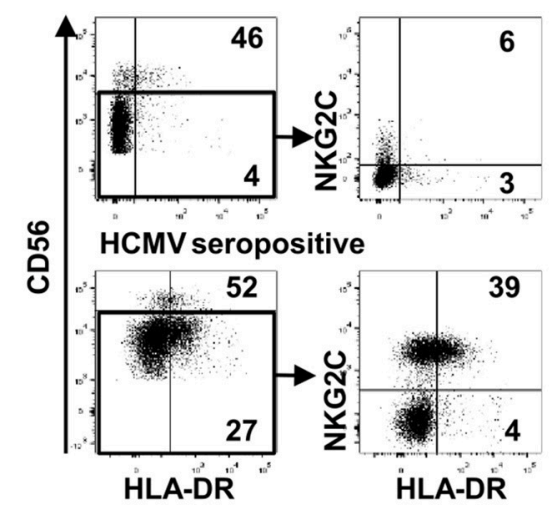

C

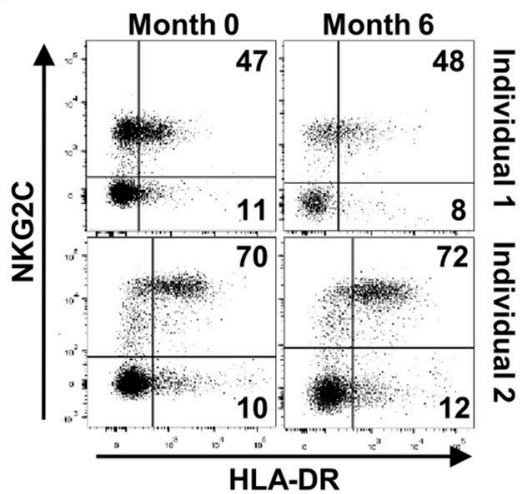

B

O HCMV- O NKG2C bright $\bullet \mathrm{NKG}^{-} \mathrm{C}^{\text {dim }}$

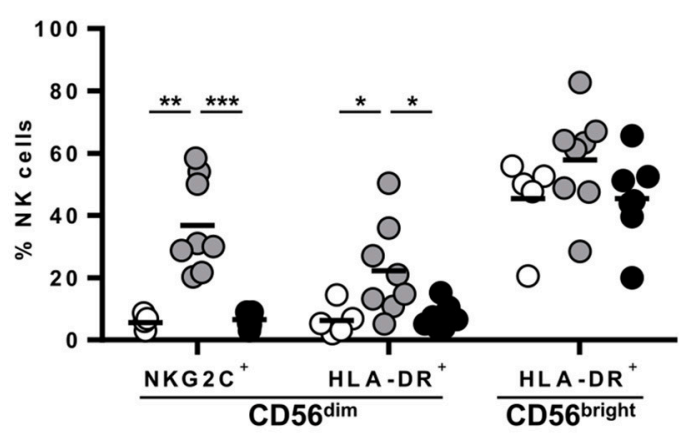

D

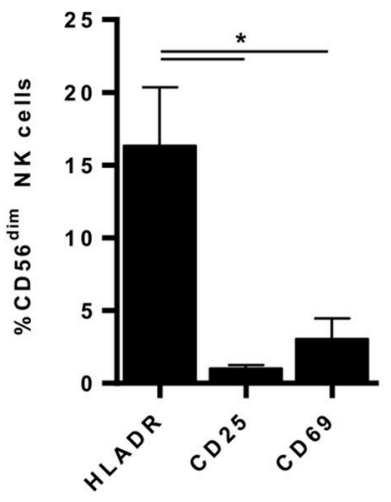

FIGURE 1 | Surface expression of HLA-DR is stably detected in variable proportions of circulating NKG2C+ adaptive NK cells in the absence of activation markers. NKG2C and HLA-DR expression was analyzed by flow cytometry in circulating NK cells from seronegative ( $n=5$; HCMV-) and seropositive (HCMV+) individuals with $\left(n=8\right.$; NKG2C ${ }^{\text {bright }}$ ) or without ( $n=7$; NKG2C dim) NKG2C+ adaptive NK cells. (A) Representative dot plots of NKG2C and HLA-DR expression in CD56 dim NK cells from HCMV- and HCMV+ individuals. Inset numbers indicate proportions of HLA-DR+ in CD56 bright and CD56 dim gates. (B) Percentage of NKG2C+ and HLA-DR+ cells in CD56 dim and CD56 bright NK cell subsets in individuals categorized according to their HCMV serology and the presence (NKG2C ${ }^{\text {bright }}$ ) or absence (NKG2C ${ }^{\text {dim }}$ ) of NKG2C+ adaptive NK cells. (C) Dot plots showing NKG2C and HLA-DR phenotype along time in two out of five HCMV+ individuals analyzed. Inset numbers indicate frequencies of HLA-DR+ cells in NKG2C+ and NKG2C- NK cells. (D) HLA-DR, CD25, and CD69 expression on circulating CD56 dim NK cells from HCMV+ individuals with NKG2C+ adaptive NK cells (mean \pm SEM, $n=6)\left({ }^{*} p<0.05,{ }^{* *} p<0.01,{ }^{* \star *} p<0.001\right)$.

of the HLA class II genotype evidenced that several of the individuals showing expansions of HLA-DR $+\mathrm{NKG} 2 \mathrm{C}+\mathrm{NK}$ cells expressed HLA class II alleles previously shown to present HCMV immunodominant peptides (i.e., HLA-DR7) (Supplementary Table I) (45).

Overall, these data indicate that circulating $\mathrm{NK}$ cells can process HCMV particles and present peptides by MHC class II to antigen-primed CD4 $+\mathrm{T}$ cells in a process that may be enhanced by stimulation with HCMV-antibody complexes.

\section{HCMV-Specific CD4+ T Cells Activated by Antigen-Loaded NK Cells Display an Effector Memory Phenotype, Lack CD28 Expression and Have Cytotoxic Potential}

We analyzed the differentiation profile of $\mathrm{CD} 4+\mathrm{T}$ cells activated in response to antigen presenting NK cells by monitoring the expression of CCR7, CD45RA, and of CD28 as previously defined $(14,46)$. CCR7 and CD45RA expression define four $\mathrm{T}$ cell populations: naïve (CD45RA+ CCR7+), central memory (CD45RA- CCR7+), effector memory (CD45RA-CCR7-) and terminally differentiated effector memory (TEMRA) (CD45RA+, CCR7-) T cells, whereas CD28 negative circulating $\mathrm{CD} 4+\mathrm{T}$ cells have been identified in individuals with chronic/persistent viral infections (e.g., HCMV) $(11,14)$. The majority of CD4+ $\mathrm{T}$ cells activated in response to HCMV-loaded NK cells displayed an effector memory (EM) or TEMRA phenotype, lacking CD28 (Figures 5A,B). In contrast, both CD28+ and CD28- effector memory CD4+ $\mathrm{T}$ cells were activated upon co-culture with HCMV-loaded moDC (Figures 5A,B). Thus, activation of CD28- memory CD4+ T cells by antigen presenting NK cells likely reflects their capacity for responding to lower HLA class II-peptide levels in the absence of $\mathrm{CD} 28$ co-stimulatory signaling. In agreement with previous reports $(11,14)$, CD28- CD4+ T cells in HCMV seropositive donors were perforin + and granzyme $\mathrm{B}+$, with 


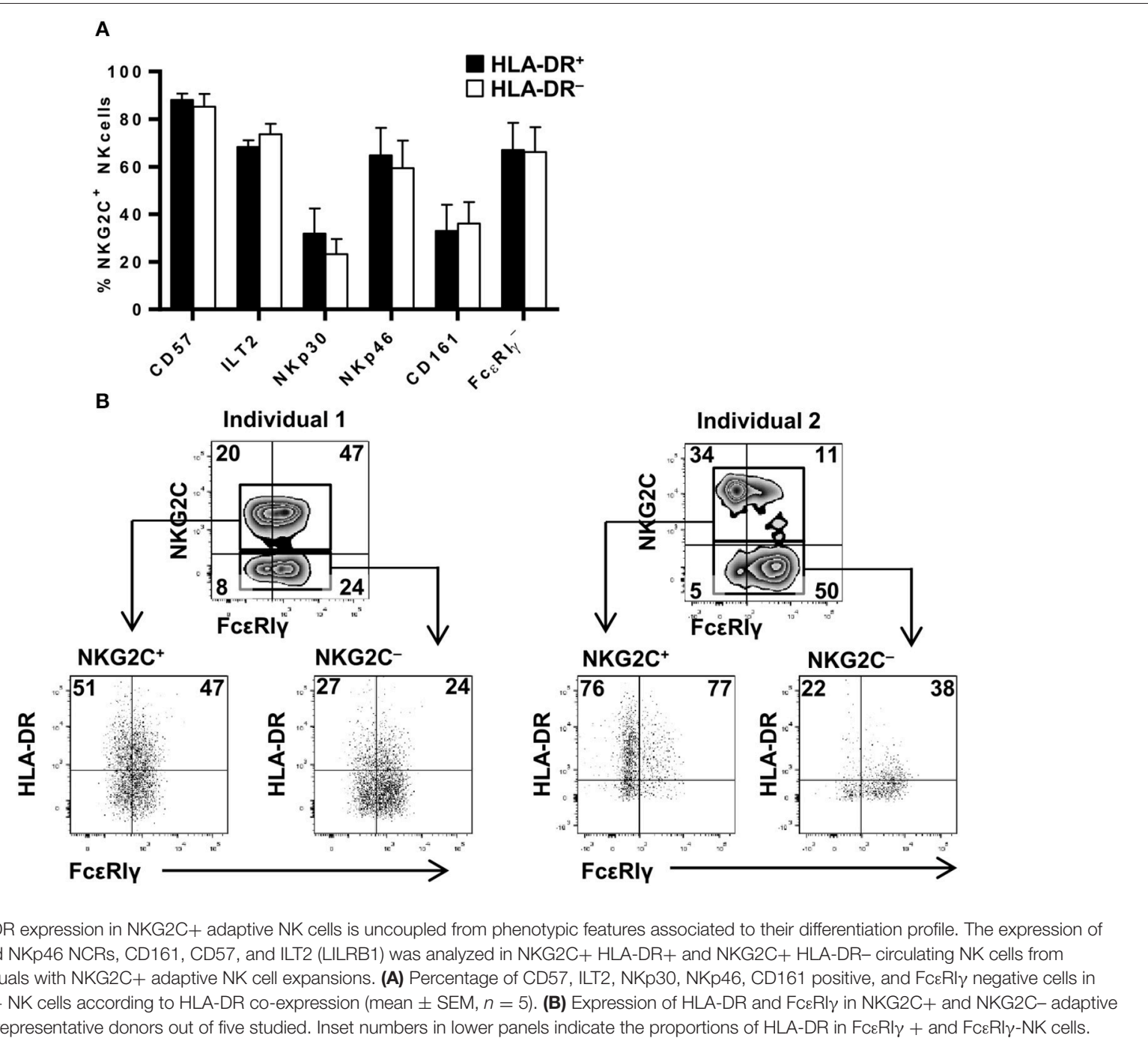

variable co-expression of the activating NK cell receptor NKG2D (Figure 5C) (47).

An assay employing autologous expanded HCMV-specific $\mathrm{CD} 4+\mathrm{T}$ cells and HLA-DR+ NKG2C+ NK cells was set up to enhance the sensitivity of the experimental system. HCMVspecific CD4+ T cells were enriched by culturing PBMC from HCMV seropositive individuals with HCMV viral particles in the presence of IL-2 as previously described (47). Under these conditions, expanded CD4 $+\mathrm{T}$ cells presented an effectormemory phenotype, high levels of perforin and granzyme B and were mostly $\mathrm{CD} 28$ positive yet with variable expression of NKG2D (Supplementary Figure 3). NKG2C+ HLA-DR+ NK cells were expanded in parallel by co-culturing PBMC with the .221-AEH cell line. After 9 days, the majority of expanded NK cells were CD16+, NKG2C+, HLA-DR+, and expressed CD86 (Supplementary Figure 4). NK cell lines were pre-loaded with HCMV particles in the presence or absence of HCMV+ serum and co-cultured with expanded CD4+ T cells. As compared to results with primary lymphocytes, average proportions of $\mathrm{CD} 4+\mathrm{T}$ cells activated by antigen-loaded NK cells in the absence or presence of HCMV+ serum was 12 to 52 -fold higher respectively, reaching up to $10 \%$ of total $\mathrm{CD} 4+\mathrm{T}$ lymphocytes (Figures 6A,B). NK cell-dependent $\mathrm{CD} 4+\mathrm{T}$ cell activation could be blocked by an anti-HLA-DR antibody (Figure 6C) and, in accordance with the primary setting, no cytokine production was detected in NK cells, ruling out their response against autologous CD4+ T cells (not shown).

\section{Antigen-Presentation by NK Cells Triggers a Polyfunctional CD4+ T Cell Response}

We next assessed whether CD4+ T cell activation by HCMVloaded NK cells was qualitatively comparable to that induced by professional APCs. For that purpose, CD4+ $\mathrm{T}$ cell degranulation as well as IFN $\gamma$ and $\mathrm{TNF} \alpha$ production were simultaneously analyzed by flow cytometry in co-culture experiments with autologous NK cells or moDC, previously incubated with $\mathrm{HCMV}$-antibody immune complexes. As shown in Figure $7, \sim 65 \%$ of primary $\mathrm{CD} 4+\mathrm{T}$ cells activated by antigen presenting NK cells secreted TNF $\alpha$ and IFN $\gamma$ whereas concomitant degranulation was detected in $\sim 35 \%$ 


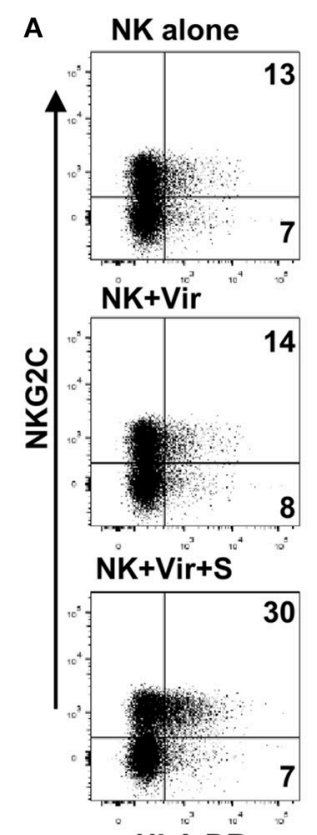

HLA-DR
C

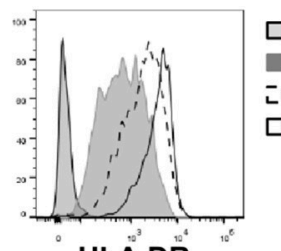

HLA-DR
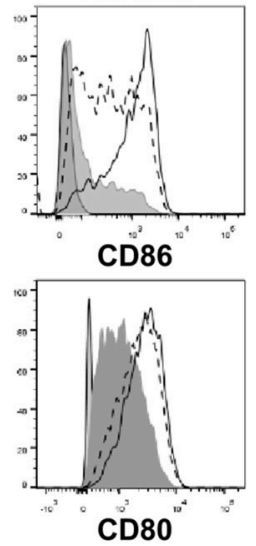

B

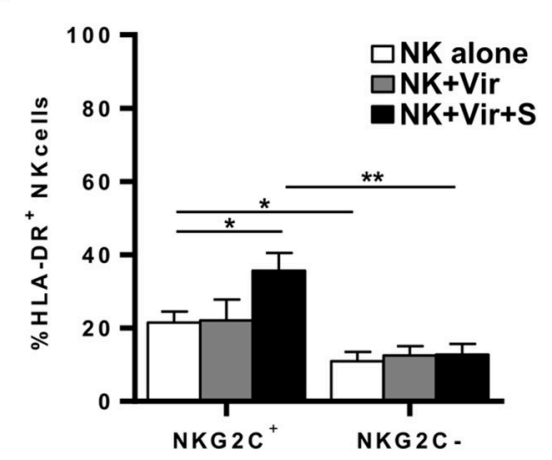

D

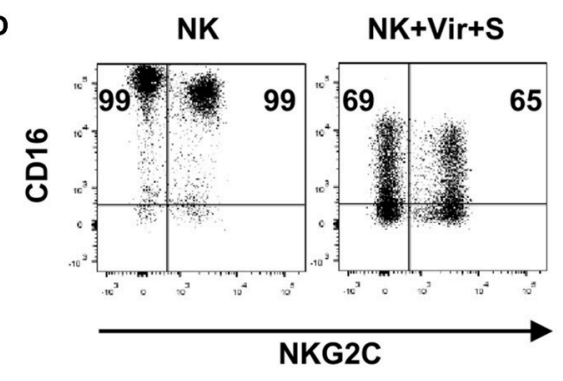

E

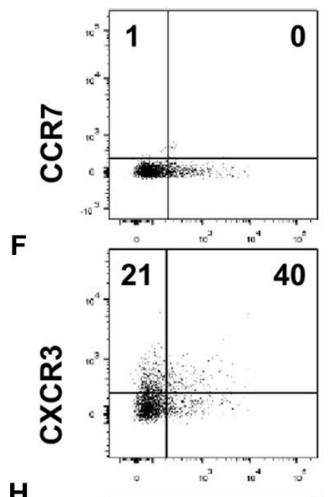

NK+Vir+S
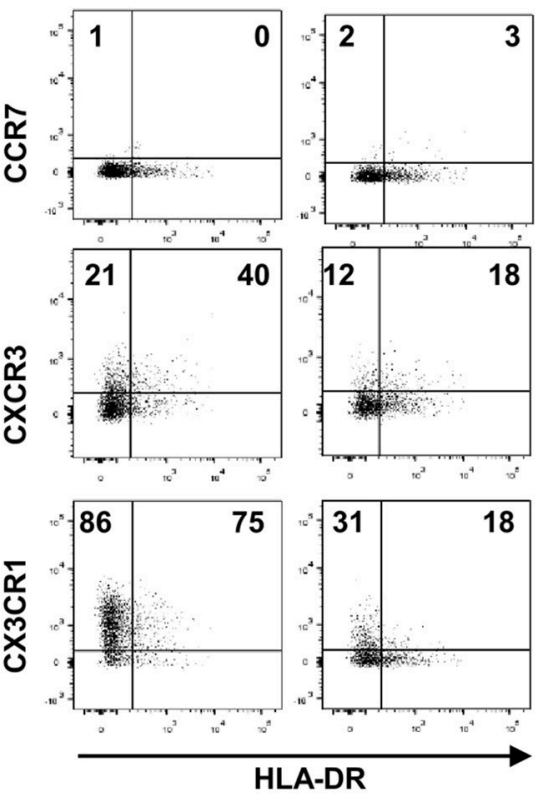

FIGURE 3 | NKG2C ${ }^{\text {bright }}$ NK cells up-regulate HLA-DR upon HCMV antigen uptake in the presence of specific antibodies. NK cells and moDC were cultured $20 \mathrm{~h}$ with HCMV viral particles in the presence or absence of serum from HCMV+ donors. Expression of HLA-DR, CD86, CD80, CD16, CCR7, CXCR3, and CX3CR1 was analyzed by flow cytometry. (A) Dot plots of HLA-DR and NKG2C expression in NK cells in the indicated conditions. Inset numbers indicate the frequency of HLA-DR+ cells in NKG2C+ and NKG2C- NK cells. Data from a representative donor out of four studied. (B) Bar graph showing the average expression of HLA-DR in $\mathrm{NKG} 2 \mathrm{C}+$ and NKG2C- NK cells in the different conditions (mean $\pm \mathrm{SEM}, n=4)\left({ }^{*} p<0.05,{ }^{* *} p<0.01\right)$. (C) Histograms displaying HLA-DR, CD86, and CD80 expression in moDC in the indicated conditions. (D) Dot plot showing CD16 and NKG2C expression in NK cells incubated or not with HCMV virions and specific serum. Inset numbers indicate percentages of CD16+ cells in NKG2C+ and NKG2C- NK cells. (E-H) Dot plot showing CCR7, CXCR3, and CX3CR1 in HLA-DR+ and HLA-DR- NK cells incubated or not with HCMV virions and specific serum. Data from one donor out of three analyzed are shown. Inset numbers indicate percentages of cells positive for each chemokine receptor in NKG2C+ and NKG2C- NK cells.

of them. Antigen presentation by moDC triggered a more heterogeneous CD4+ $\mathrm{T}$ cell response including $\sim 15 \%$ of cells degranulating in the absence of cytokine production, $\sim 60 \%$ of cells producing pro-inflammatory cytokines and $\sim 40 \%$ of cells showing a polyfunctional response with concomitant degranulation and cytokine production. In co-cultures using expanded $\mathrm{NK}$ and $\mathrm{CD} 4+\mathrm{T}$ cells up to $\sim 75 \%$ of the responding $\mathrm{CD} 4+\mathrm{T}$ cells degranulated and produced $\mathrm{TNF} \alpha$ and IFN $\gamma$ (Figures 7B-E).

\section{DISCUSSION}

HCMV promotes in some individuals an adaptive reconfiguration of the $\mathrm{NK}$ cell compartment characterized by the persistent expansion of a subset of NKG2C + NK cells (15). These adaptive NK cells display a particular phenotypic and functional profile, efficiently mediating antibody-dependent NK cell responses against virus-infected cells (20-22). Pre-transplant expansions of NKG2C+ adaptive NK cells have been associated 


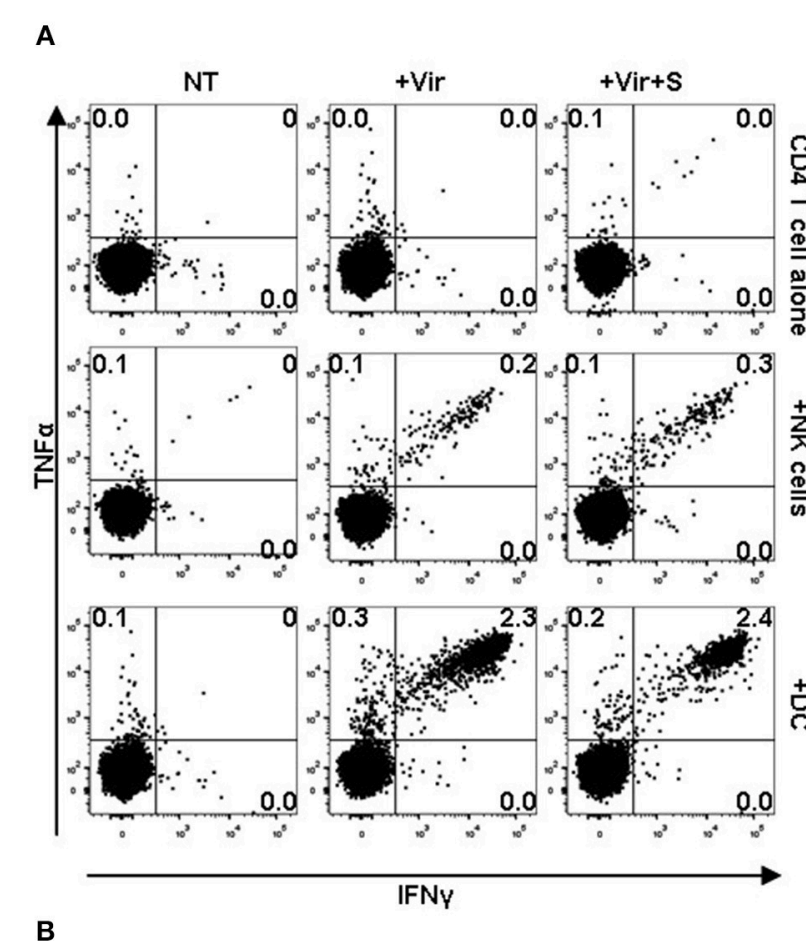

C

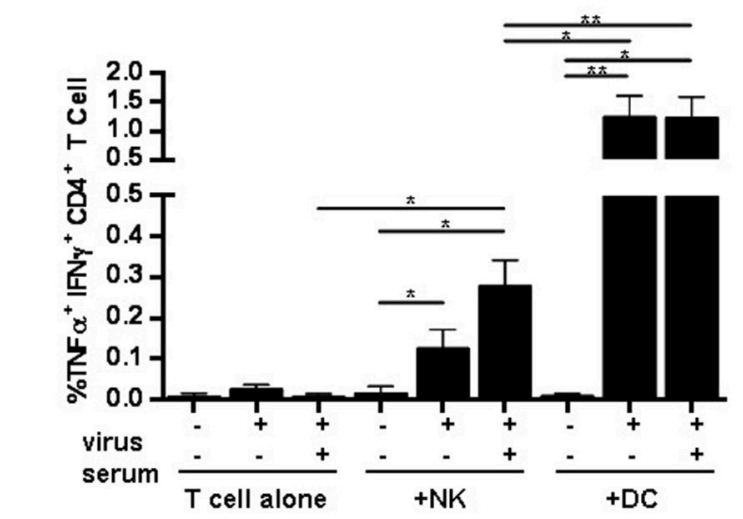

$\stackrel{+}{\circ} \quad \mathbf{D}$

$\mathbf{F}$
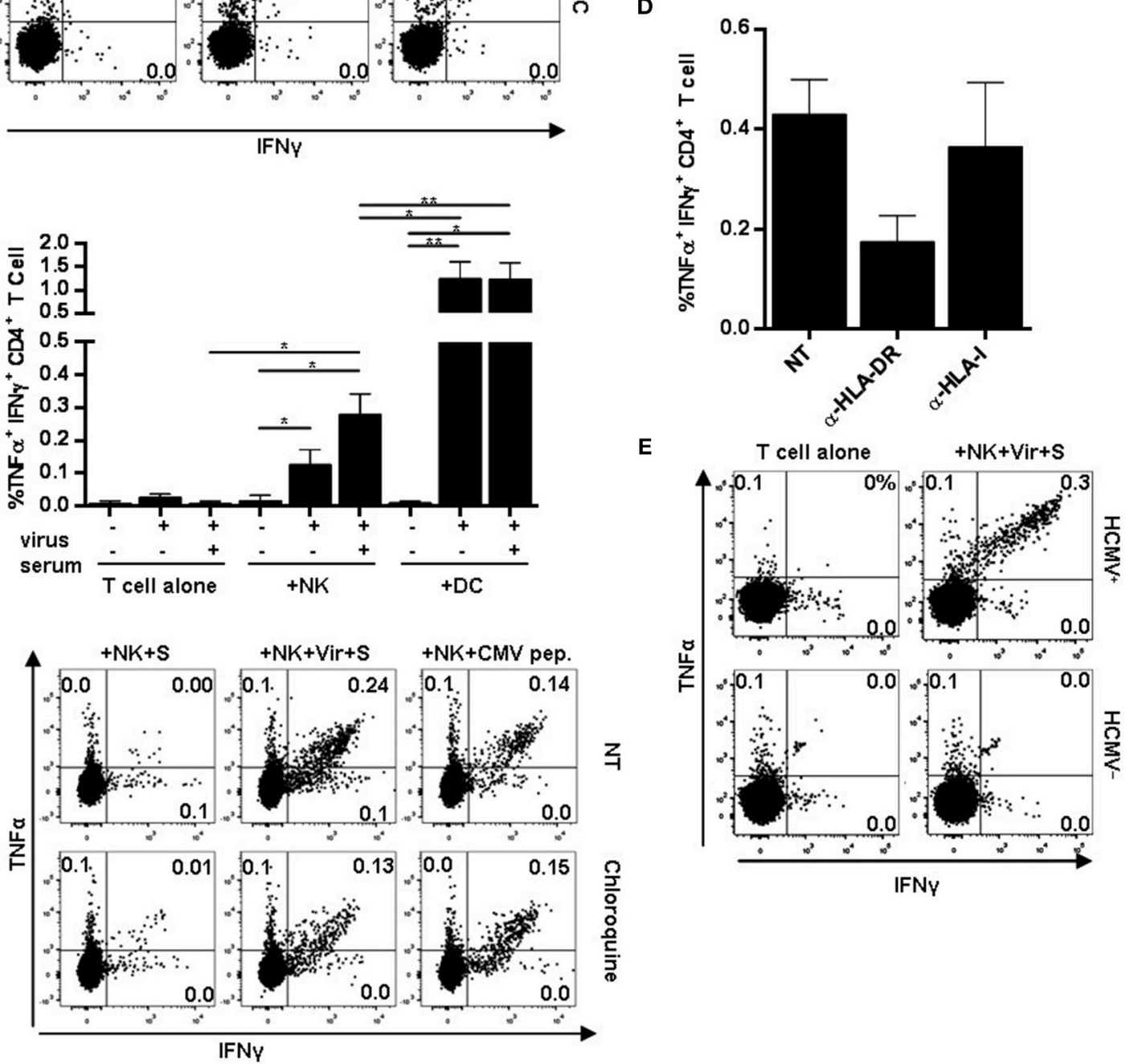

E

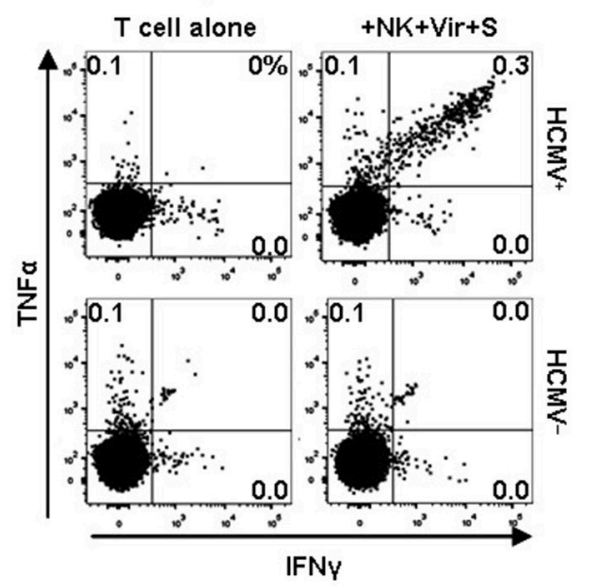

FIGURE 4 | CD4+ T cell activation in response to HCMV antigen presentation by NK or moDC. NK cells or moDCs previously loaded with HCMV-antibody immune complexes were cultured overnight with autologous CD4+ T cells. TNF $\alpha$ and IFN $\gamma$ production was analyzed by flow cytometry. (A) TNF $\alpha$ and IFN $\gamma$ production by CD4+ T cells in the indicated conditions. Data from a representative donor out of five tested. (B) Mean frequency of IFN $\gamma+$ and TNF $\alpha+C D 4+T$ cells upon activation with different APCs (mean \pm SEM, $n=5)\left({ }^{\star} p<0.05,{ }^{* \star} p<0.01\right)$. (C-E) Autologous PBMC were used as effectors in co-culture experiments with NK cells

(Continued) 
FIGURE 4 | pre-incubated with HCMV-antibody immune complexes. CD4+ and CD8+ T cell activation was analyzed by flow cytometry. An agonist anti-CD3 antibody was used as a positive control. (C) Dot plots display intracellular TNF $\alpha$ and IFN $\gamma$ in CD4+ and CD8+ T cells in the indicated conditions. Data from a representative donor out of four analyzed. (D) Frequency of TNF $\alpha+$ and IFN $\gamma+C D 4+T$ cells in response to HCMV-loaded NK cells in the presence of blocking antibodies specific for HLA-DR and HLA class I molecules (mean \pm SEM, $n=3$ ). (E) TNF $\alpha$ and IFN $\gamma$ intracellular staining of CD4+ T cells in co-cultures including antigen-presenting NK cells and autologous PBMC from HCMV seropositive and seronegative individuals. (F) Frequency of TNF $\alpha+$ and IFN $\gamma+$ CD4+ T cells in response to HCMV-loaded NK cells. NK cells were loaded in the presence or absence of chloroquine $(50 \mu \mathrm{M})$. Dot plots of one out of two donors tested.

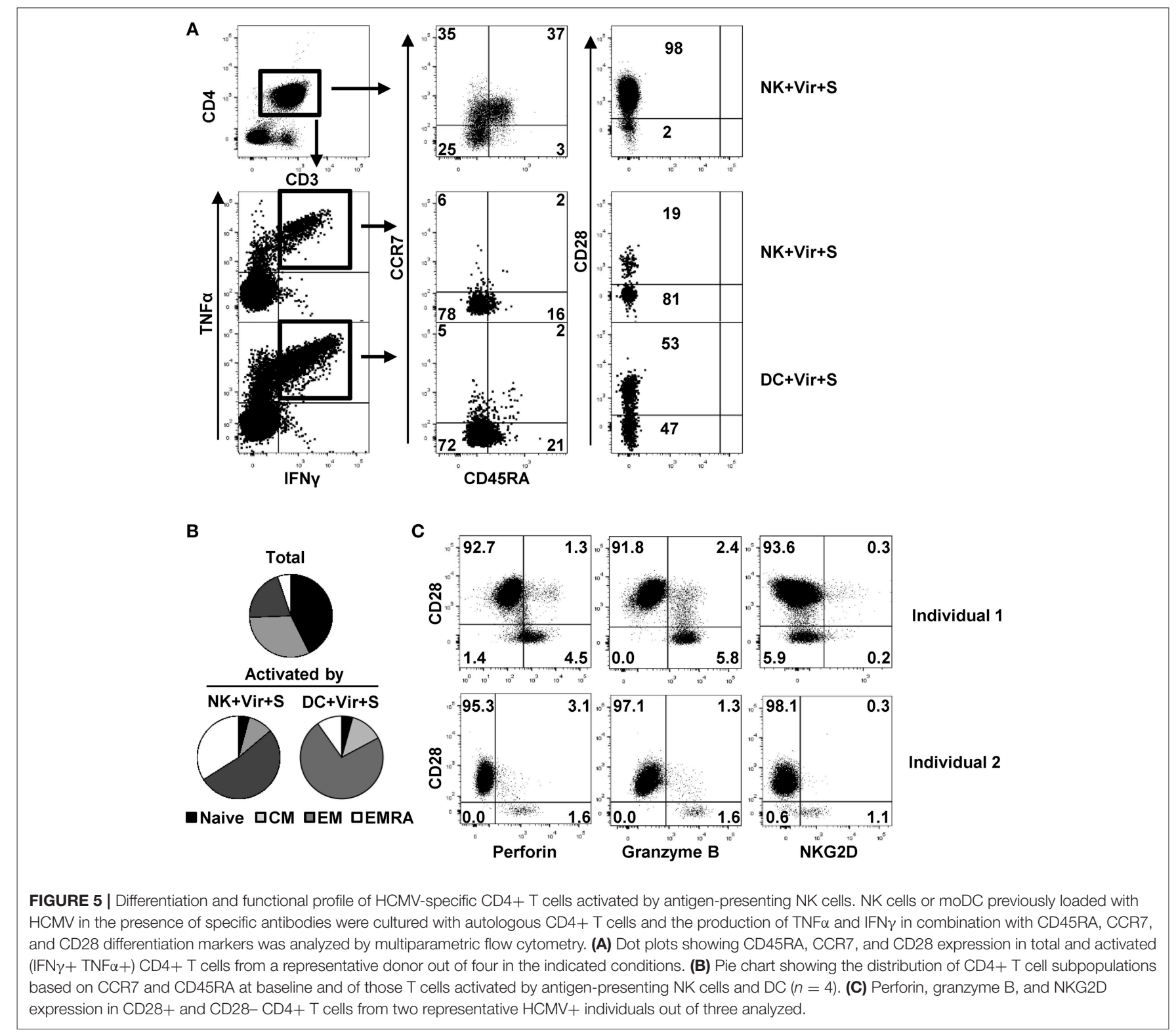

to a reduced incidence of HCMV viremia in kidney transplant recipients (23). In the current study, we have analyzed a novel functional feature of NKG2C+ adaptive NK cells related to their expression of HLA class II molecules. Our data demonstrates the preferential and persistent expression of HLA-DR in circulating NKG2C+ adaptive NK cells among the CD56 ${ }^{\mathrm{dim}}$ subset, as well as their capacity for processing and presenting HCMV antigens to effector memory $\mathrm{CD} 4+\mathrm{T}$ cells, triggering a polyfunctional
Th1/cytotoxic response. HCMV immune complexes enhanced antigen presentation. Whether this process may regulate in vivo the development of HCMV-specific memory CD4+ T cell responses, contributing to the control of viral reactivation, deserves attention.

HLA class II expression on a variable fraction of peripheral blood NK cells, mainly coinciding with CD56 bright NK cells, had been previously described in healthy individuals $(30,31)$. 
A

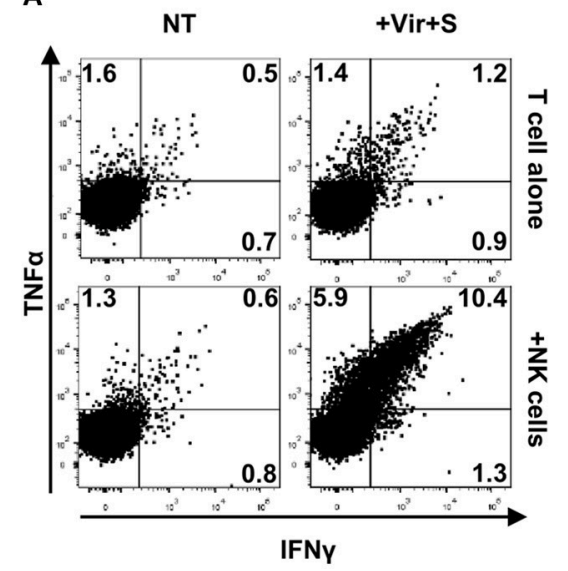

B

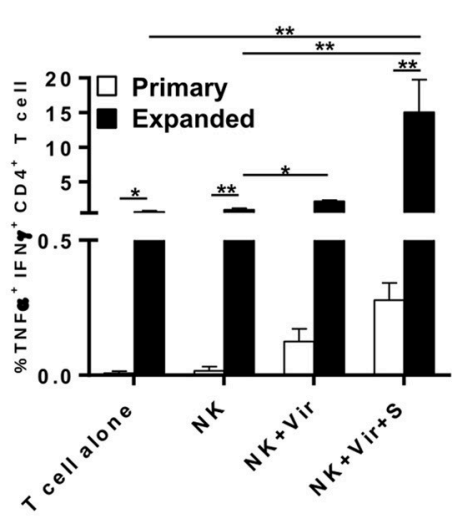

C

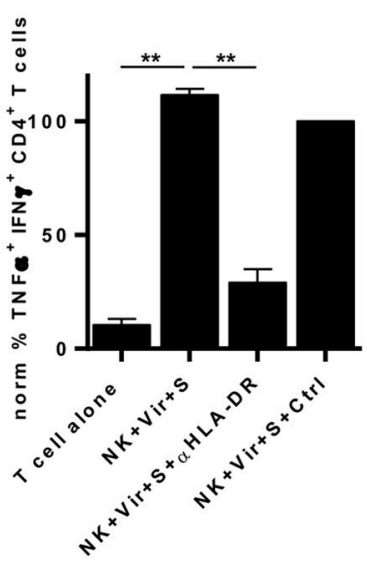

FIGURE 6 | Antigen presentation by expanded HLA-DR+ NKG2C+ NK cells to HCMV-specific autologous CD4+ T cell lines. Expanded NKG2C+ NK cells pre-loaded with HCMV in the presence of immune serum were cultured overnight with HCMV-expanded CD4+ T cells. Intracellular TNF $\alpha$ and IFN $\gamma$ was analyzed by flow cytometry. (A) TNF $\alpha$ and IFN $\gamma$ in CD4+ T cells cultured in the indicated conditions. Data from a representative donor. (B) Comparison of the frequency of TNF $\alpha+$ IFN $\gamma+$ CD $4+T$ cells in co-culture experiments using primary or expanded antigen presenting and effector cells (mean \pm SEM, $n=5)\left({ }^{*} p<0.05,{ }^{* *} p<0.01\right)$. (C) Frequency of TNF $\alpha+$ IFN $\gamma+$ HCMV-expanded CD4+ T cells upon co-culture with antigen-loaded NK cells in the presence of an $\alpha$-HLA-DR (clone D1.12) or an isotype control (mean \pm SEM, $n=5$ ).

The analysis of transcriptional programs in adaptive NKG2C+ NK cells identified MHC class II antigen presentation as an enriched functional pathway in this NK cell subset $(24,25)$ (Supplementary Figure 1). Our phenotypic studies including selected healthy blood donors with known NK cell receptor repertoires confirmed that HLA-DR+CD56 ${ }^{\mathrm{dim}} \mathrm{NK}$ cells were more frequently detected in $\mathrm{HCMV}+$ individuals coinciding, though not exclusively, with a variable fraction of $\mathrm{NKG} 2 \mathrm{C}+$ adaptive NK cells. Whether HLA-DR expression on NKG2C+ adaptive NK cells reflected a reversible activation state or was associated with their differentiation was addressed. The fact that surface HLA-DR was uncoupled from the expression of activation markers and co-stimulatory molecules, remaining stable along the follow-up, rather supported its association with a differentiation status of adaptive NK cells. However, HLADR expression appeared unrelated to the levels of FceRI $\gamma$ and other adaptive NK cell differentiation markers (i.e., CD57 and LILRB1). It is conceivable that epigenetic remodeling associated with adaptive NK cell differentiation $(24,48)$ might facilitate transcription of CIITA (49) and other HLA class II related genes in a fraction of adaptive NK cells contributing to their functional specialization.

Previous studies addressing HLA class II function on NK cells have tested soluble peptides $(33,34)$ and Staphylococcal Enterotoxin B crosslinking (32) for triggering HLA-class II-dependent $\mathrm{CD} 4+\mathrm{T}$ cell activation, hence bypassing the requirement for whole antigen uptake, processing and presentation by the NK cell. Expanded NK cell clones were shown to process and present HLA class II-dependent peptides derived from soluble proteins though failed to present whole Mycobacterium leprae (50). The herein presented results showed that NK cells can, indeed, perform these processes upon direct or antibody-aided interaction with viral preparations. It is plausible that our viral preparations contained non-infectious particles or viral antigens facilitating the uptake by a non-professional antigen presenting cell such as NK cells, nonetheless, their decreased antigen presenting function in experiments including chloroquine, indirectly supported their capability for processing and presenting exogenously-added HCMV-derived antigens through HLA class II. Direct viral antigen uptake could be mediated by TLR2 binding with $\mathrm{gB}$ and $\mathrm{gH}$ HCMV envelope proteins (51), an interaction previously involved in type I IFN production leading to NK cell priming (44). Our data indicate that incubation with HCMV-antibody immune complexes promoted a partial NK cell activation evidenced by low degranulation and the production of $\mathrm{TNF} \alpha$ in the absence of IFN $\gamma$ (21) as well as a partial down-regulation of CD16, concomitant to increased surface HLA-DR levels (Figure 3). The formation of viral antigen-antibody immune complexes could facilitate their uptake prior to CD16 shedding resulting from NK cell activation $(52,53)$. On the other hand, the increase in HLA-DR surface levels on NK cells in these conditions might also enhance antigen presentation to CD4 $+\mathrm{T}$ cells. The capacity of $\mathrm{Fc} \gamma \mathrm{R}$ for enhancing antigen uptake has been extensively described in APCs such as DCs and macrophages $(54,55)$. In professional APCs antigen uptake through immune complexes enhances antigen presentation and cross-presentation through HLA class II and I respectively, allowing the simultaneous activation of specific CD4+ and CD8 $+\mathrm{T}$ cells (56). Our data showed that presence of HCMV-antibody immune complexes enhanced HLA class II-dependent antigen presentation by NK cells though did not appear to detectably enable simultaneous HLA class I-mediated cross-presentation of viral-derived antigens activating CD8 $+\mathrm{T}$ cells. Observations in functional assays supported that the absence of co-stimulatory molecules together with their relatively low levels of surface 
A

B

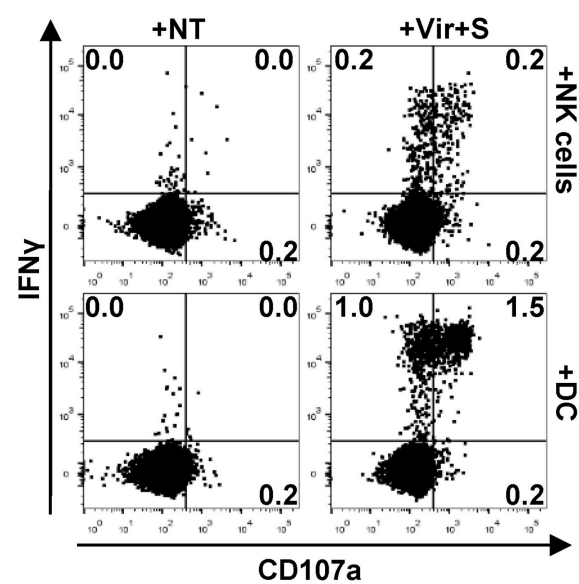

C

NK+Vir+S

DC+Vir+S
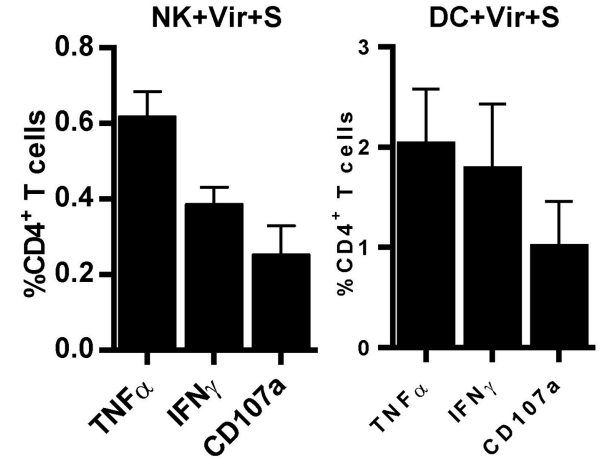

D
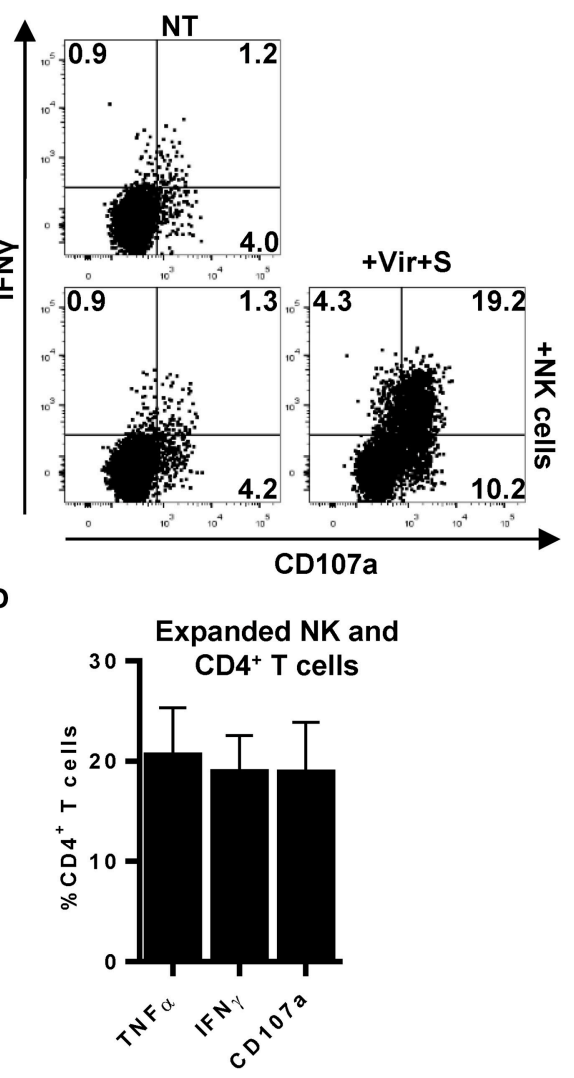

E
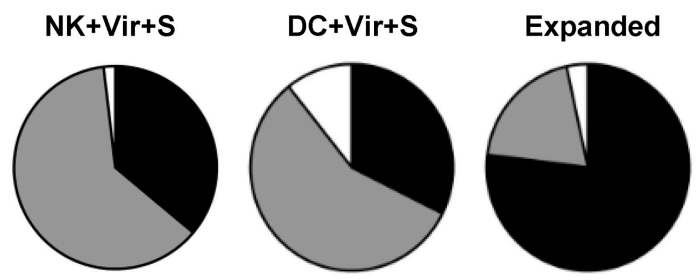

Cytokines + CD107a

$\square$ Cytokines

$\square$ CD107a

FIGURE 7 | Primary and expanded HCMV-specific CD4+ T cells degranulate in response to antigen loaded NK and moDC. TNF $\alpha$ and IFN $\gamma$ production concomitant to CD107a mobilization was monitored by flow cytometry in co-culture experiments combining HCMV-loaded primary NK cells or moDC with primary autologous CD4+ T cells $\mathbf{( A , C , E ) ~ o r , ~ a l t e r n a t i v e l y , ~ a n t i g e n ~ l o a d e d ~ e x p a n d e d ~ N K ~ c e l l s ~ a n d ~ H C M V - e x p a n d e d ~ C D 4 + ~ T ~ c e l l s ~ ( B , D , E ) . ~ ( A , B ) ~ D o t ~ p l o t s ~ d i s p l a y i n g ~ t h e ~ p r o p o r t i o n s ~ o f ~}$ IFN $\gamma+$ CD107a + CD4 + T cells in the primary (A) and expanded (B) experimental systems. Data from a representative experiment. (C,D) Proportions of TNF $\alpha+$, IFN $\gamma+$, and CD107+ CD4+ T cells in the different experimental systems assayed (mean+SEM; $n=4)$. (E) Pie charts showing the distribution of CD4+ T cells that produce cytokines and degranulate against HCMV-loaded APC in the indicated experimental systems $($ mean; $n=4)$.

HLA-DR in steady state resulted in an antigen presenting function of adaptive NK cells, yet less fitted in comparison to professional APCs.

The fraction of HCMV-specific CD4+ T cells activated by NK cells was confined into the atypical CD28- effectormemory pool with cytotoxic potential, previously described in association with HCMV infection (11, 12, 57). HCMV-loaded moDCs activated both CD28- and CD28+ effector memory $\mathrm{CD} 4+\mathrm{T}$ cells likely as a result from presenting a broader virusderived peptide repertoire in the context of higher HLA class II surface expression and CD80/CD86 co-stimulatory ligands. It is likely that the expression of specific HLA class II molecules capable of presenting immunodominant HCMV antigens such as HLA-DR7 or HLA-DP10 $(11,45,58)$ may also influence on the antigen presenting capacity of NK cells, as previously described for other non-professional APCs such as fibroblasts (59). Actually, gB-specific CD4 $+\mathrm{T}$ cell responses were found in $95 \%$ of healthy donors ranging from 0.002 to $2.8 \%$ of the $\mathrm{CD} 4+\mathrm{T}$ cell pool and did not require de novo protein synthesis (59). Studies analyzing the peptide repertoires associated to HLA class II in NK as compared to DC would shed light on these issues. Antigen presentation by NK cells induced a polyfunctional CD4+ $\mathrm{T}$ cell activation, qualitatively resembling that detected when using moDC as APCs, characterized by the production of 
Th1 cytokines and the secretion of their cytotoxic granules, in a fraction of activated cells. Since we only monitored IFN $\gamma$ and $\mathrm{TNF} \alpha$ production, main anti-viral cytokines dominating HCMVspecific $\mathrm{CD} 4+\mathrm{T}$ cell responses, we cannot exclude the capacity of NK cells for also activating the minority of IL-4, IL-17, or IL10-producing HCMV-specific CD4+ T cells reported in some individuals $(11,12,60)$.

Regarding the consequences of the cognate interaction between autologous cytotoxic CD4+ $\mathrm{T}$ lymphocytes and antigen-presenting NK cells, the latter did not degranulate in co-culture experiments ruling out their activation. On the other hand, whether cytotoxic CD4+ $\mathrm{T}$ cells may specifically kill antigen-loaded HLA-DR+ NK cells is conceivable yet the possibility that adaptive NK cells may be resistant to the $\mathrm{CD} 4+\mathrm{T}$ cell cytolytic machinery is not ruled out, as reported for the interaction between memory $\mathrm{CD} 8+\mathrm{T}$ cells and DC (61).

An additional open question is where antigen presentation by NK cells to specific effector memory CD4 $+\mathrm{T}$ cells may take place and to what extent this mechanism could contribute to HCMV infection control. It is tempting to speculate that antigen presentation by $\mathrm{NKG} 2 \mathrm{C}+$ adaptive $\mathrm{NK}$ cells may take place at the site of viral reactivation since antigen availability and the chemokine receptor profile expressed by adaptive NK and effector memory CD4+ T cells (CCR7-, CXCR $3^{\text {low }}$, CX3CR1+) might preferentially direct them to non-lymphoid/inflamed tissues. Even though performing less efficiently than professional APCs, NK cell-mediated HLA class-II dependent antigen presentation could promote $\mathrm{CD} 4+\mathrm{T}$ cell responses to HCMV, counteracting its ability to infect professional APC (i.e., dendritic cells or macrophages) $(62,63)$.

In summary, we have described a novel facet of HCMVinduced NKG2C+ adaptive NK cells residing in their capacity

\section{REFERENCES}

1. Crumpacker C. Cytomegalovirus. In: Mandell GL, Benett JE, Dolin R, editors. Mandell, Douglas, and Benett's Principles and Practice of Infectious Diseases. 5th ed. Philadelphia, PA: Churchill Livingstone (2000). p. 1586-99.

2. Boeckh M, Ljungman $\mathrm{P}$. How we treat cytomegalovirus in hematopoietic cell transplant recipients. Blood. (2009) 113:5711-9. doi: 10.1182/blood-2008-10-143560

3. Fishman JA. Infection in solid-organ transplant recipients. $N$ Engl J Med. (2007) 357:2601-14. doi: 10.1056/NEJMra064928

4. Pass RF, Fowler KB, Boppana SB, Britt WJ, Stagno S. Congenital cytomegalovirus infection following first trimester maternal infection: symptoms at birth and outcome. J Clin Virol. (2006) 35:216-20. doi: 10.1016/j.jcv.2005.09.015

5. Brodin P, Jojic V, Gao T, Bhattacharya S, Angel CJL, Furman D, et al. Variation in the human immune system is largely driven by non-heritable influences. Cell. (2015) 160:37-47. doi: 10.1016/j.cell.2014.12.020

6. Crough T, Khanna R. Immunobiology of human cytomegalovirus: from bench to bedside. Clin Microbiol Rev. (2009) 22:76-98. doi: 10.1128/CMR.00034-08

7. Klenerman P, Oxenius A. T cell responses to cytomegalovirus. Nat Rev Immunol. (2016) 16:367-77. doi: 10.1038/nri.2016.38

8. Sester M, Sester U, Gärtner B, Kubuschok B, Girndt M, Meyerhans A, et al. Sustained high frequencies of specific CD4 T cells restricted to a single persistent virus. J Virol. (2002) 76:3748-55. doi: 10.1128/JVI.76.8.3748-3755.2002 to present antigens to HCMV-specific CD4+ T cells in an HLADR-dependent manner, triggering a polyfunctional activation of the cytotoxic effector memory $\mathrm{T}$ cell pool.

\section{AUTHOR CONTRIBUTIONS}

MC-G carried out the experimental work and wrote an initial draft. MA collaborated in the analysis of publically available expression data and experimental work. MM and CV analyzed HLA class II genotypes. AM and ML-B contributed to the design, follow up and interpretation of the results, and wrote the final draft that was revised by all authors.

\section{FUNDING}

The authors are supported by Plan Estatal I+D Retos (SAF201680363-C2-1-R/-2-R), Spanish Ministry of Economy and Competitiveness (MINECO, FEDER); EU FP7-MINECO Infect-ERA program (PCIN-2015-191-C02-01/02); Fundación Española contra el Cáncer (GCB15152947MELE); Proyecto Integrado de Excelencia ISCIII (PIE 2015/00008); and Worldwide Cancer Research Foundation (15-1146).

\section{ACKNOWLEDGMENTS}

The authors thank Gemma Heredia and Andrea Vera for technical help, and Oscar Fornas for advice in flow cytometry.

\section{SUPPLEMENTARY MATERIAL}

The Supplementary Material for this article can be found online at: https://www.frontiersin.org/articles/10.3389/fimmu. 2019.00687/full\#supplementary-material

9. Pourgheysari B, Khan N, Best D, Bruton R, Nayak L, Moss PAH. The cytomegalovirus-specific CD4+ T-cell response expands with age and markedly alters the CD4+ T-cell repertoire. J Virol. (2007) 81:7759-65. doi: 10.1128/JVI.01262-06

10. van Leeuwen EM, Remmerswaal EB, Heemskerk MH, ten Berge IJ, van Lier RA. Strong selection of virus-specific cytotoxic CD4+ T-cell clones during primary human cytomegalovirus infection. Blood. (2006) 108:3121-7. doi: 10.1182/blood-2006-03-006809

11. Pachnio A, Ciaurriz M, Begum J, Lal N, Zuo J, Beggs A, et al. Cytomegalovirus infection leads to cevelopment of high frequencies of cytotoxic virusspecific CD4+ T cells targeted to vascular endothelium. PLOS Pathog. (2016) 12:e1005832. doi: 10.1371/journal.ppat.1005832

12. Jackson SE, Sedikides GX, Mason GM, Okecha G, Wills MR. Human cytomegalovirus (HCMV)-specific CD4 $+\mathrm{T}$ cells are polyfunctional and can respond to HCMV-infected dendritic cells in vitro. J Virol. (2017) 91:e0212816. doi: 10.1128/JVI.02128-16

13. Rentenaar RJ, Gamadia LE, van DerHoek N, van Diepen FN, Boom $\mathrm{R}$, Weel JF, et al. Development of virus-specific $\mathrm{CD}^{+}{ }^{+} \mathrm{T}$ cells during primary cytomegalovirus infection. J Clin Invest. (2000) 105:541-8. doi: 10.1172/JCI8229

14. van Leeuwen EM, Remmerswaal EB, Vossen MT, Rowshani AT, Wertheimvan Dillen PM, van Lier RA, et al. Emergence of a CD4+CD28granzyme $\mathrm{B}+$, cytomegalovirus-specific $\mathrm{T}$ cell subset after recovery of primary cytomegalovirus infection. J Immunol. (2004) 173:1834-41. doi: 10.4049/jimmunol.173.3.1834 
15. Gumá M, Angulo A, Vilches C, Gómez-Lozano N, Malats N, López-Botet M. Imprint of human cytomegalovirus infection on the NK cell receptor repertoire. Blood. (2004) 104:3664-71. doi: 10.1182/blood-2004-05-2058

16. López-Botet M, Muntasell A, Vilches C. The CD94/NKG2C+ NK-cell subset on the edge of innate and adaptive immunity to human cytomegalovirus infection. Semin Immunol. (2014) 26:145-51. doi: 10.1016/j.smim.2014. 03.002

17. Béziat V, Liu L, Malmberg J-A, Ivarsson MA, Sohlberg E, Björklund AT, et al. NK cell responses to cytomegalovirus infection lead to stable imprints in the human KIR repertoire and involve activating KIRs. Blood. (2013) 121:2678-88. doi: 10.1182/blood-2012-10-459545

18. Muntasell A, López-Montañés M, Vera A, Heredia G, Romo N, Peñafiel J, et al. NKG2C zygosity influences CD94/NKG2C receptor function and the NK-cell compartment redistribution in response to human cytomegalovirus. Eur J Immunol. (2013) 43:3268-78. doi: 10.1002/eji.201343773

19. Lopez-Vergès S, Milush JM, Schwartz BS, Pando MJ, Jarjoura J, York VA, et al. Expansion of a unique $\mathrm{CD} 57^{+} \mathrm{NKG} 2 \mathrm{Chi}$ natural killer cell subset during acute human cytomegalovirus infection. Proc Natl Acad Sci USA. (2011) 108:14725-32. doi: 10.1073/pnas.1110900108

20. Zhang T, Scott JM, Hwang I, Kim S. Cutting Edge: antibody-dependent memory-like NK cells distinguished by FcR $\gamma$ deficiency. J Immunol. (2013) 190:1402-6. doi: 10.4049/jimmunol.1203034

21. Costa-Garcia M, Vera A, Moraru M, Vilches C, López-Botet $M$, Muntasell A. Antibody-mediated response of NKG2Cbright NK cells against human cytomegalovirus. J Immunol. (2015) 194:2715-24. doi: 10.4049/jimmunol.1402281

22. Wu Z, Sinzger C, Frascaroli G, Reichel J, Bayer C, Wang L, et al. HCMV induced NKG2ChiCD57hi natural killer cells are effectors depending on humoral antiviral immunity. J Virol. (2013) 87:7717-25. doi: 10.1128/JVI.01096-13

23. Redondo-Pachón D, Crespo M, Yélamos J, Muntasell A, Pérez-Sáez MJ, PérezFernández S, et al. Adaptive NKG2C + NK cell response and the risk of cytomegalovirus infection in kidney transplant recipients. J Immunol. (2017) 198:94-101. doi: 10.4049/jimmunol.1601236

24. Schlums H, Cichocki F, Tesi B, Theorell J, Beziat V, Holmes TD, et al. Cytomegalovirus infection drives adaptive epigenetic diversification of NK cells with altered signaling and effector function. Immunity. (2015) 42:443-56. doi: 10.1016/j.immuni.2015.02.008

25. Lee J, Zhang T, Hwang I, Kim A, Nitschke L, Kim M, et al. Epigenetic modification and antibody-dependent expansion of memory-like NK cells in human cytomegalovirus-infected individuals. Immunity. (2015) 42:431-42. doi: 10.1016/j.immuni.2015.02.013

26. Kambayashi T, Laufer TM. Atypical MHC class II-expressing antigenpresenting cells: can anything replace a dendritic cell? Nat Rev Immunol. (2014) 14:719-30. doi: 10.1038/nri3754

27. Fogli M, Costa P, Murdaca G, Setti M, Mingari MC, Moretta L, et al. Significant NK cell activation associated with decreased cytolytic function in peripheral blood of HIV-1-infected patients. Eur J Immunol. (2004) 34:231321. doi: 10.1002/eji.200425251

28. Aranami T, Miyake S, Yamamura T. Differential expression of CD11c by peripheral blood NK cells reflects temporal activity of multiple sclerosis. $J$ Immunol. (2006) 177:5659-67. doi: 10.4049/jimmunol.177.8.5659

29. Cruz-González D de J, Gómez-Martin D, Layseca-Espinosa E, Baranda L, Abud-Mendoza C, Alcocer-Varela J, et al. Analysis of the regulatory function of natural killer cells from patients with systemic lupus erythematosus. Clin Exp Immunol. (2017) 191:288-300. doi: 10.1111/cei.13073

30. Sedlmayr P, Schallhammer L, Hammer A, Wilders-Truschnig M, Wintersteiger R, Dohr G. Differential phenotypic properties of human peripheral blood CD56dim + and CD56bright+ natural killer cell subpopulations. Int Arch Allergy Immunol. (1996) 110:308-13. doi: $10.1159 / 000237321$

31. Erokhina SA, Streltsova MA, Kanevskiy LM, Telford WG, Sapozhnikov AM, Kovalenko EI. HLA-DR+ NK cells are mostly characterized by less mature phenotype and high functional activity. Immunol Cell Biol. (2018) 96:212-28. doi: 10.1111/imcb.1032

32. D'Orazio JA, Stein-Streilein J. Human natural killer (NK) cells present staphylococcal enterotoxin B (SEB) to T lymphocytes. Clin Exp Immunol. (1996) 104:366-73.
33. Burt BM, Plitas G, Nguyen HM, Stableford JA, Bamboat ZM, DeMatteo RP. Circulating HLA-DR+ natural killer cells have potent lytic ability and weak antigen-presenting cell function. Hum Immunol. (2008) 69:469-74. doi: 10.1016/j.humimm.2008.06.009

34. Kim M, Osborne NR, Zeng W, Donaghy H, McKinnon K, Jackson DC, et al. Herpes simplex virus antigens directly activate NK cells via TLR2, thus facilitating their presentation to CD4 T lymphocytes. J Immunol. (2012) 188:4158-70. doi: 10.4049/jimmunol.1103450

35. Oliphant CJ, Hwang YY, Walker JA, Salimi M, Wong SH, Brewer JM, et al. MHCII-mediated dialog between group 2 innate lymphoid cells and CD4+ T cells potentiates type 2 immunity and promotes parasitic helminth expulsion. Immunity. (2014) 41:283-95. doi: 10.1016/j.immuni.2014.06.016

36. Hepworth MR, Monticelli LA, Fung TC, Ziegler CGK, Grunberg S, Sinha $\mathrm{R}$, et al. Innate lymphoid cells regulate $\mathrm{CD} 4+\mathrm{T}$-cell responses to intestinal commensal bacteria. Nature. (2013) 498:113-7. doi: 10.1038/nature12240

37. Maecker HT, Frey T, Nomura LE, Trotter J. Selecting fluorochrome conjugates for maximum sensitivity. Cytometry A. (2004) 62A:169-73. doi: 10.1002/cyto.a.20092

38. Muntasell A, Magri G, Pende D, Angulo A, López-Botet M. Inhibition of NKG2D expression in NK cells by cytokines secreted in response to human cytomegalovirus infection. Blood. (2010) 115:5170-9. doi: 10.1182/blood-2009-11-256479

39. Kovalenko EI, Streltsova MA, Kanevskiy LM, Erokhina SA, Telford WG. Identification of human memory-like NK cells. Curr Protoc Cytom. (2017) 79:9.50.1-11. doi: 10.1002/cpcy.13

40. Magri G, Muntasell A, Romo N, Sáez-Borderías A, Pende D, Geraghty DE, et al. NKp46 and DNAM-1 NK-cell receptors drive the response to human cytomegalovirus-infected myeloid dendritic cells overcoming viral immune evasion strategies. Blood. (2011) 117:848-56. doi: 10.1182/blood-2010-08-301374

41. Lee N, Goodlett DR, Ishitani A, Marquardt H, Geraghty DE. HLA-E surface expression depends on binding of TAP-dependent peptides derived from certain HLA class I signal sequences. J Immunol. (1998) 160:4951-60.

42. Muntasell A, Pupuleku A, Cisneros E, Vera A, Moraru M, Vilches C, et al. Relationship of NKG2C copy number with the distribution of distinct cytomegalovirus-induced adaptive NK cell subsets. J Immunol. (2016) 196:3818-27. doi: 10.4049/jimmunol.1502438

43. Liu LL, Landskron J, Ask EH, Enqvist M, Sohlberg E, Traherne JA, et al. Critical role of $\mathrm{CD} 2$ co-stimulation in adaptive natural killer cell responses revealed in NKG2C-deficient humans. Cell Rep. (2016) 15:1088-99. doi: 10.1016/j.celrep.2016.04.005

44. Muntasell A, Costa-Garcia M, Vera A, Marina-Garcia NN, Kirschning CJ, López-Botet M, et al. Priming of NK cell anti-viral effector mechanisms by direct recognition of human cytomegalovirus. Front Immunol. (2013) 4:40. doi: 10.3389/fimmu.2013.00040

45. Sylwester AW, Mitchell BL, Edgar JB, Taormina C, Pelte C, Ruchti F, et al. Broadly targeted human cytomegalovirus-specific CD4+ and CD8 + T cells dominate the memory compartments of exposed subjects. J Exp Med. (2005) 202:673-85. doi: 10.1084/jem.20050882

46. Alonso-Arias R, Moro-García MA, López-Vázquez A, Rodrigo L, Baltar J, García FMS, et al. NKG2D expression in CD4+ T lymphocytes as a marker of senescence in the aged immune system. AGE. (2011) 33:591-605. doi: 10.1007/s11357-010-9200-6

47. Sáez-Borderías A, Gumá M, Angulo A, Bellosillo B, Pende D, LópezBotet M. Expression and function of NKG2D in CD4+ T cells specific for human cytomegalovirus. Eur J Immunol. (2006) 36:3198-206. doi: $10.1002 /$ eji.200636682

48. Lau CM, Adams NM, Geary CD, Weizman O-E, Rapp M, Pritykin Y, et al. Epigenetic control of innate and adaptive immune memory. Nat Immunol. (2018) 19:963-72. doi: 10.1038/s41590-018-0176-1

49. Wright KL, Ting JP-Y. Epigenetic regulation of MHC-II and CIITA genes. Trends Immunol. (2006) 27:405-12. doi: 10.1016/j.it.2006.07.007

50. Roncarolo MG, Bigler M, Haanen JB, Yssel H, Bacchetta R, de Vries JE, et al. Natural killer cell clones can efficiently process and present protein antigens. $J$ Immunol. (1991) 147:781-7.

51. Boehme KW, Guerrero M, Compton T. Human cytomegalovirus envelope glycoproteins $\mathrm{B}$ and $\mathrm{H}$ are necessary for TLR2 activation in permissive cells. $J$ Immunol. (2006) 177:7094-102. doi: 10.4049/jimmunol.177.10.7094 
52. Romee R, Foley B, Lenvik T, Wang Y, Zhang B, Ankarlo D, et al. NK cell CD16 surface expression and function is regulated by a disintegrin and metalloprotease-17 (ADAM17). Blood. (2013) 121:3599-608. doi: 10.1182/blood-2012-04-425397

53. Goodier MR, Lusa C, Sherratt S, Rodriguez-Galan A, Behrens R, Riley EM. Sustained Immune Complex-Mediated Reduction in CD16 Expression after Vaccination Regulates NK Cell Function. Front Immunol. (2016) 7:384. doi: 10.3389/fimmu.2016.00384

54. Lanzavecchia A. Receptor-mediated antigen uptake and its effect on antigen presentation to class II-restricted T lymphocytes. Annu Rev Immunol. (1990) 8:773-93. doi: 10.1146/annurev.iy.08.040190.004013

55. Bournazos S, Wang TT, Ravetch JV. The role and function of FC $\gamma$ receptors on myeloid cells. Microbiol Spectr. (2016) 4:MCHD-0045-2016. doi: 10.1128/microbiolspec.MCHD-0045-2016

56. Platzer B, Stout M, Fiebiger E. Antigen cross-presentation of immune complexes. Front Immunol. (2014) 5:140. doi: 10.3389/fimmu.2014.00140

57. Fletcher JM, Vukmanovic-Stejic M, Dunne PJ, Birch KE, Cook JE, Jackson $\mathrm{SE}$, et al. Cytomegalovirus-specific CD4+ T cells in healthy carriers are continuously driven to replicative exhaustion. J Immunol. (2005) 175:821825. doi: 10.4049/jimmunol.175.12.8218

58. Ventura C, Bisceglia H, Girerd-Chambaz Y, Burdin N, Chaux P. HLA-DR and HLA-DP restricted epitopes from human cytomegalovirus glycoprotein B recognized by CD4+ T-cell clones from chronically infected individuals. $J$ Clin Immunol. (2012) 32:1305-16. doi: 10.1007/s10875-012-9732-x

59. Pachnio A, Zuo J, Ryan GB, Begum J, Moss PAH. The cellular localization of human cytomegalovirus glycoprotein expression greatly influences the frequency and functional phenotype of specific CD4+ T cell responses. $J$ Immunol. (2015) 195:3803-15. doi: 10.4049/jimmunol.1500696
60. Wunsch M, Zhang W, Hanson J, Caspell R, Karulin AY, Recks MS, et al. Characterization of the HCMV-specific CD4 T cell responses that are associated with protective immunity. Viruses. (2015) 7:4414-37. doi: 10.3390/v7082828

61. Watchmaker PB, Urban JA, Berk E, Nakamura Y, Mailliard RB, Watkins SC, et al. Memory CD8 + T cells protect dendritic cells from CTL killing. $J$ Immunol. (2008) 180:3857-65. doi: 10.4049/jimmunol.180.6.3857

62. Cebulla CM, Miller DM, Zhang Y, Rahill BM, Zimmerman P, Robinson JM, et al. Human cytomegalovirus disrupts constitutive MHC class II expression. J Immunol. (2002) 169:167-76. doi: 10.4049/jimmunol.169. 1.167

63. Hegde NR, Tomazin RA, Wisner TW, Dunn C, Boname JM, Lewinsohn DM, et al. Inhibition of HLA-DR assembly, transport, and loading by human cytomegalovirus glycoprotein US3: a novel mechanism for evading major histocompatibility complex class II antigen presentation. J Virol. (2002) 76:10929-41. doi: 10.1128/JVI.76.21.10929-10941.2002

Conflict of Interest Statement: The authors declare that the research was conducted in the absence of any commercial or financial relationships that could be construed as a potential conflict of interest.

Copyright (c) 2019 Costa-García, Ataya, Moraru, Vilches, López-Botet and Muntasell. This is an open-access article distributed under the terms of the Creative Commons Attribution License (CC BY). The use, distribution or reproduction in other forums is permitted, provided the original author(s) and the copyright owner(s) are credited and that the original publication in this journal is cited, in accordance with accepted academic practice. No use, distribution or reproduction is permitted which does not comply with these terms. 